\title{
Procainamide and phenytoin
}

\section{Comparative study of their antiarrhythmic effects at apparent therapeutic plasma levels}

\author{
Erling Karlsson \\ From the Departments of Internal Medicine (Division of Cardiology) and Clinical Pharmacology, University of \\ Linköping, Linköping, Sweden
}

\begin{abstract}
The antiarrhythmic effects of procainamide and phenytoin were studied in 81 patients admitted to the coronary care unit at the University Hospital in Linköping because of a suspected or proven diagnosis of acute myocardial infarction, and who developed ventricular arrhythmias, requiring treatment, during the first 8 hours in hospital. Patients were randomly allocated to a procainamide or phenytoin group. The drugs were given as intravenous and oral loading doses followed by oral maintenance therapy. Plasma levels of the two drugs were frequently determined and the electrocardiogram was continuously recorded during the 24-hour trial and analysed minute by minute. A significantly higher frequency of therapeutic failure was found in the phenytoin group (23 of 35 patients) compared to the procainamide group ( 13 of 39 patients) during the first 2 hours after initiation of therapy. Four patients in the phenytoin group and 2 in the procainamide group developed symptoms probably caused by the trial drugs, necessitating discontinuation of therapy. The mean plasma levels were usually within the apparent therapeutic range (for phenytoin 40-72 $\mu \mathrm{mol} / \mathrm{l}(\mathrm{IO}-18 \mu \mathrm{g} / \mathrm{ml}$ ), and for procainamide I7-34 $\mu \mathrm{mol} / \mathrm{l}(4-8 \mu \mathrm{g} / \mathrm{ml})$. Seventeen patients $(68 \%)$ in the phenytoin group and Io patients $(48 \%)$ in the procainamide group had plasma concentrations within this range when the therapeutic failure was observed. Nine patients died in hospital but only one of them during the trial. The results of this investigation clearly demonstrate the overall superiority of procainamide over phenytoin as an antiarrhythmic drug in short-term therapy after acute myocardial infarction.
\end{abstract}

Both experimental and clinical observations suggest that ventricular premature beats usually precede and initiate life-threatening cardiac arrhythmias (Julian, Valentine, and Miller, 1964; Lown et al., 1967; Bleifeld and Merx, 1970; Mogensen, 1970; Dhurandhar, MacMillan, and Brown, 1971; Lown and Wolf, 1971; Merx et al., 1971; Bennet and Pentecost, 1972). For this reason suppressive therapy is commonly instituted in the early postinfarction period. The initial therapy is usually lignocaine infusion which is replaced, one or two days later, by oral antiarrhythmic drugs. Of these, procainamide and phenytoin are frequently used compounds, but no controlled prospective trial has been published on their relative efficacy. This paper presents such an evaluation in patients with suspected or proven acute myocardial infarction during the first 24 hours after admission to hospital.

Received 7 October 1974.

\section{Patients}

The material comprised patients admitted to the coronary care unit at the University Hospital in Linköping with a suspected or proven diagnosis of myocardial infarction. Only patients with ventricular arrhythmias developing within 8 hours of admission and requiring treatment according to criteria set by Lown et al. $(1967)^{1}$ were included in the study.

Excluded from the study were patients with: atrioventricular block of second and third degree and of first degree if in combination with bifascicular block; a heart rate of 50 beats a minute or less; ventricular fibrillation; persistent ventricular tachycardia calling for immediate electroconversion; a systolic pressure of $90 \mathrm{mmHg}$ $(12.0 \mathrm{kPa})$ or less; pulmonary oedema or cardiogenic shock; uraemia; a history of asthma, collagen disease, or drug hypersensitivity. Patients receiving antiarrhythmic therapy of any kind, except for cardiac glycosides, 1 The electrocardiographic criteria are described in detail on page 732 . 
on admission, and patients in whom any kind of intracardiac catheterization was performed were also excluded.

The basic therapy included nasal administration of oxygen for about 24 hours, anticoagulant therapy (dicoumarol) if not contraindicated, pentazocine and/or hydromorphone-atropine for analgesia, and diazepam for sedation. Heart failure was conveniently treated by diuretics and digitalis. No antiarrhythmic drugs except those studied were given during the trial.

On admission blood samples were drawn for determination of haemoglobin, serum creatinine, electrolytes, serum bilirubin, serum levels of aspartate aminotransferase, alanine aminotransferase, lactate dehydrogenase, creatine phosphokinase, and a plasma blank.

The diagnosis of acute myocardial infarction was based on at least two of the following conventional criteria: (I) history of central chest pain of at least 15 minutes' duration; (2) sequential and localized electrocardiographic changes of ST segments and T waves, and/or development of $Q$ waves; (3) appropriate enzyme increases; (4) findings at necropsy of myocardial necrosis of an age corresponding to the onset of symptoms.

\section{Programme of antiarrhythmic therapy}

Patients who fulfilled the criteria for inclusion in the trial were allocated to the procainamide or the phenytoin group, according to a randomized numerical code. At the first observation by the coronary care unit nurses of a ventricular arrhythmia requiring treatment, the patient received therapy. The following doses were chosen from the results of preliminary studies as yielding appropriate plasma concentration levels.

I) $5 \mathrm{mg} / \mathrm{kg}$ body weight of the allocated drug was given as an intravenous bolus at a rate of $25 \mathrm{mg} / \mathrm{min}$. Simultaneously an oral dose of either procainamide $(\mathrm{I} .5 \mathrm{~g})$ as a sustained release preparation (Karlsson, I973) or phenytoin ( $0.7 \mathrm{~g}$ ) as sodium salt (Epanutin) was given.

2) Fifteen minutes after the first injection was finished another intravenous bolus dose of either procainamide $(2.5 \mathrm{mg} / \mathrm{kg}$ ) or phenytoin ( $\mathrm{I} \mathrm{mg} / \mathrm{kg}$ ) was given at the same rate.

3) The maintenance therapy was started at least 2 hours after the second bolus injection and administered eight hourly at 6 a.m., 2 p.m., and Io p.m. The daily dose of phenytoin was $0.3 \mathrm{~g}$ and that of procainamide was $3 \mathrm{~g}$ for a body weight of $\leqslant 75 \mathrm{~kg}$ and $4.5 . \mathrm{g}$ for a body weight of $>75 \mathrm{~kg}$.

The treatment was discontinued at therapeutic failure or if serious side-effects developed during the trial, i.e. either side-effects fulfilling the same criteria as those used to exclude a patient from the trial, or the occurrence of vertigo with a duration of 30 minutes or more, nystagmus, ataxia, vomiting, etc. All side-effects were recorded.

Venous blood samples for drug concentration assay were drawn from the arm not used for intravenous injections. The samples were taken at the end of and 2 hours after the start of the first injection and just before the last dose, i.e. I6 to 24 hours after the start of the first injection. Blood samples were also drawn at the time of therapeutic failure or suspected or proven sideeffects. In more than half of the patients blood samples were taken at more frequent intervals, i.e. just before and at the end of the second injection, $I, I \frac{1}{2}, 2 \frac{1}{2}, 3$, and 8 hours after the start of the first injection.

\section{Analytical technique}

All blood samples were centrifuged within one hour and the plasma was frozen until analysed, which was done within 2 weeks for all samples.

Phenytoin was analysed by the gas chromatographic method of Berlin et al. (1972) and procainamide by spectrophotofluorimetry as described by Koch-Weser and Klein (I97I), but with the substitution of benzene for toluene.

\section{Electrocardiographic recordings}

The electrocardiogram was continuously monitored during the entire trial on a bedside oscilloscope and on a slave oscilloscope above the nurses' desk. The monitored electrocardiogram was also continuously recorded on an 8-channel ink-jet electrocardiograph recorder (Mingograph 8I, Siemens-Elema, Stockholm) at a paper speed of ro mm per second. The procedure for electrocardiographic recording was similar to that described by Mogensen (1970).

\section{Electrocardiographic analysis}

The continuous electrocardiogram for the 24 hours of the trial or until the patient was excluded from the study was analysed by the author. The various types of ventricular arrhythmias were classified minute by minute according to frequency and the following criteria:

I) Ventricular ectopic beat was defined as a premature QRS complex with a duration of more than $0.10 \mathrm{~s}$, a configuration different from the regular QRS complex and without a preceding premature $P$ wave.

2) Paired ventricular ectopic beats were defined as 2 beats in sequence.

3) Multifocal ventricular ectopic beats were defined as 2 or more with different configurations registered within the same 5-minute period.

4) $R$ on $T$ type ventricular ectopic beat was defined as one starting within the first 85 per cent of the QT time from the onset of the preceding QRS complex.

5) Ventricular tachycardia was defined as 3 or more ventricular ectopic beats in sequence and with a rate of 120 beats per minute or more. If the rate was less than 120 beats per minute the rhythm was termed rapid idioventricular rhythm and was recorded separately.

6) Ventricular fibrillation was defined as fast, irregular oscillations of varying amplitudes and without any similarity to QRS complexes.

Ventricular arrhythmias requiring treatment were those described by Lown et al. (I967): ventricular ectopic beats $>5 / \mathrm{min}$, paired, multifocal, $R$ on $T$ type, or ventricular tachycardia, defined according to the criteria above. 


\section{Results}

\section{Patient characteristics}

The trial was started in September 1973 and terminated 8 months later in April 1974. During this period 574 patients were admitted to the coronary care unit because of suspected acute myocardial infarction, and of these 195 developed ventricular arrhythmias requiring treatment according to Lown's criteria presented above. No less than II4 of these 195 patients were excluded. Some of the most frequent reasons for exclusion were: 25 patients were already receiving maintenance therapy with antiarrhythmic drugs; 25 patients did not present an arrhythmia until after 8 hours of monitoring; I4 patients showed ventricular fibrillation or persistent ventricular tachycardia necessitating immediate DC countershock followed by lignocaine infusion; II patients had bradyarrhythmias; 9 patients had pulmonary oedema or cardiogenic shock; and 6 showed conduction defects. The remaining 24 patients were excluded for various other reasons.

Included in the study were $8 \mathrm{I}$ patients, com-

TABLE I Patient characteristics on admission

\begin{tabular}{|c|c|c|c|c|}
\hline & $\begin{array}{l}\text { Procai } \\
\text { group } \\
n=42 \\
\text { No. }\end{array}$ & $\begin{array}{l}\text { inamide } \\
\text { Per cent }\end{array}$ & $\begin{array}{l}\text { Phenyt } \\
\text { group } \\
n=39 \\
\text { No. }\end{array}$ & $\begin{array}{l}\text { toin } \\
\text { Per cent }\end{array}$ \\
\hline \multicolumn{5}{|l|}{ Age (years) } \\
\hline $40-49$ & 3 & 7 & 2 & 5 \\
\hline $50-59$ & 6 & 14 & 6 & 15 \\
\hline $60-69$ & 20 & 48 & 16 & $4 \mathrm{I}$ \\
\hline $70-79$ & II & 26 & 12 & 31 \\
\hline $80-89$ & 2 & 5 & 2 & 5 \\
\hline $90-99$ & 0 & 0 & $\mathbf{I}$ & 3 \\
\hline \multicolumn{5}{|l|}{ Sex } \\
\hline Male & 30 & $7 \mathrm{I}$ & 28 & 72 \\
\hline Female & 12 & 29 & II & 28 \\
\hline \multicolumn{5}{|l|}{$\begin{array}{l}\text { Previous myocardial } \\
\text { infarction }\end{array}$} \\
\hline None & 35 & 83 & 34 & 87 \\
\hline I & 4 & IO & 3 & 8 \\
\hline 2 or more & 3 & 7 & 2 & 5 \\
\hline Heart failure on admission & 2 & 5 & $\mathbf{x}$ & 3 \\
\hline \multicolumn{5}{|l|}{ History of angina } \\
\hline $\begin{array}{l}\text { pectors } \\
\text { History of hypertension }\end{array}$ & 10 & $\begin{array}{l}43 \\
24\end{array}$ & 20 & 31 \\
\hline \multicolumn{5}{|l|}{ Maintenance therapy with } \\
\hline Digitalis & 10 & 24 & 6 & 15 \\
\hline Diuretics & 8 & 19 & 4 & 10 \\
\hline Antihypertensive drugs & 7 & 17 & 4 & 10 \\
\hline \multicolumn{5}{|l|}{ Admission delay $(\mathrm{hr})$} \\
\hline Mean \pm SD & \multirow{2}{*}{\multicolumn{2}{|c|}{$\begin{array}{l}8 \pm 9 \\
1-39\end{array}$}} & \multirow{2}{*}{\multicolumn{2}{|c|}{$\begin{array}{l}9 \pm 8 \\
I-30\end{array}$}} \\
\hline Range & & & & \\
\hline
\end{tabular}

$\star$ During $>2$ weeks before admission. prising 58 men and 23 women, who all met the criteria described earlier. The mean age of all the patients was 66 years. Forty-two of the patients were allocated to the procainamide group and 39 to the phenytoin group. Pertinent characteristics of the patients on admission are shown in Table I with a comparison between the two groups. Some clinical and laboratory data obtained during the trial and the subsequent period in hospital are given in Table 2. The two groups were similar in

TABLE 2 Clinical and laboratory findings

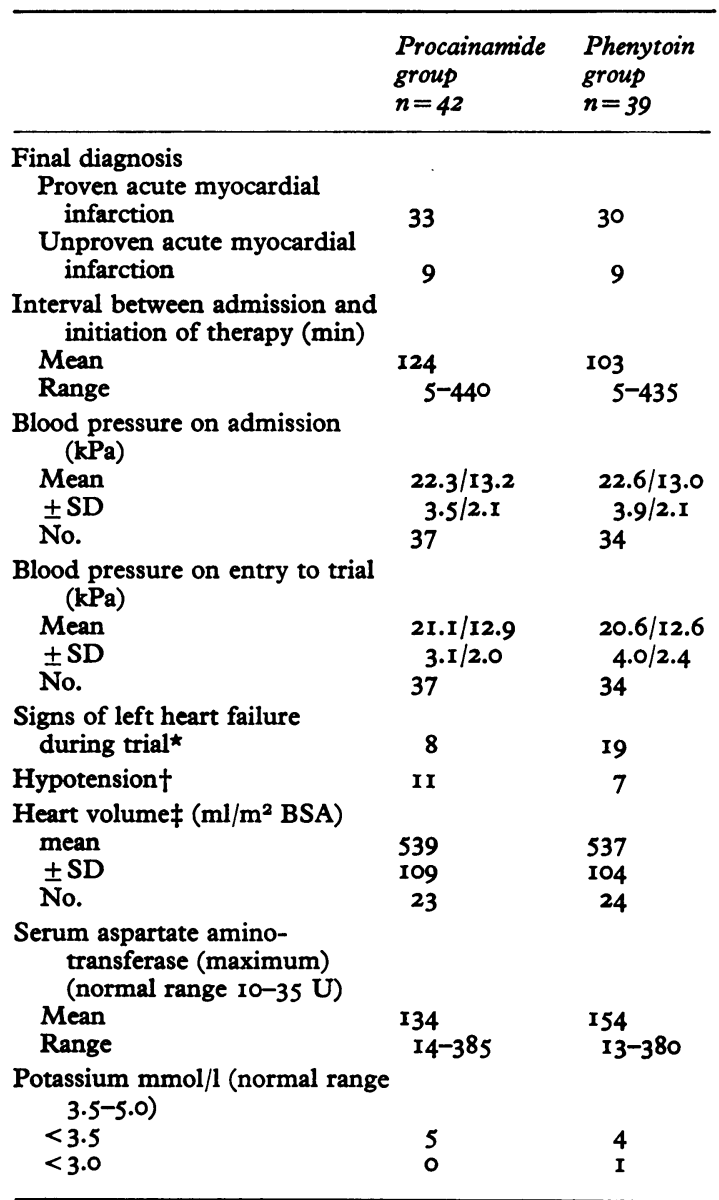

* Symptoms leading to treatment with digitalis and/or diuretics.

† Systolic blood pressure $\leqslant 13.3 \mathrm{kPa}$ or a fall of $4.0 \mathrm{kPa}$ during first 3 hours of trial.

$¥$ Measured during last days in hospital. BSA = body surface area.

Conversion from SI Units to Traditional Units: I $\mathrm{kPa} \approx$ $7.5 \mathrm{mmHg}$.

$N B$ : Figures for blood pressure and heart volume were only available for $37 / 42,34 / 39$ and $23 / 42,24 / 39$ cases. 
respect of all the characteristics examined. Heart rate, $P Q, Q R S$, and $Q T$ intervals on entry into the study were also measured; there was no difference in these between the two treatment groups. Thus, observed differences in antiarrhythmic activity and side-effects between the two treatment groups may be attributed to the difference between the two drugs.

\section{Antiarrhythmic effect}

The proportion of patients with and without therapeutic failure per I-hour interval after entry into the trial is shown in Fig. I.

In Table 3 the same values are given for the first 6 hours of the trial, which was the most interesting period, particularly because the phenytoin group

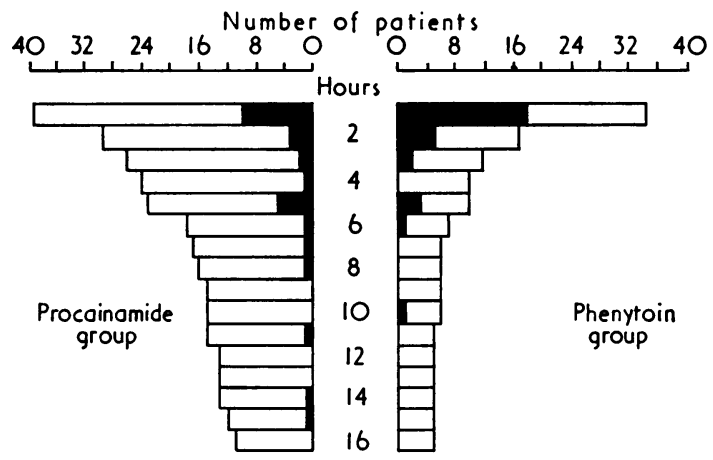

FIG. I Number of patients in each group with ( $\square$ ) and without $(\square)$ therapeutic failure per I-hour interval during the first 16 hours of the trial. All patients with both proven and unproven acute myocardial infarction are included except 7 patients developing probable side-effects after the loading doses (see text). became so small after this time as the result of the high incidence of therapeutic failure.

Four patients in each group developed suspected side-effects which necessitated discontinuance of therapy. For this reason 7 patients were excluded from the trial within the first hour after the loading dose and one patient (in the procainamide group) after 8 hours. These patients will be described in detail below.

The types of ventricular arrhythmias at failure are shown in Table 4. The most serious arrhythmias, i.e. $R$ on $T$ type of ventricular ectopic beats, ventricular tachycardia, and ventricular fibrillation, only appeared among patients with proven myocardial infarction. $R$ on $T$ type of ventricular ectopic beats were more frequent in the procainamide group. However, this type of arrhythmia was also more frequent in this group before entry into the trial, being recorded in 7 patients compared to only I patient in the phenytoin group. The frequency of ventricular tachycardia was on the other hand the same in the two groups.

Patients with both proven and unproven (failure to fulfil the criteria above) acute myocardial infarction showed a higher frequency of therapeutic failure in the phenytoin group. These differences between the procainamide and phenytoin groups were statistically significant during the first 2 hours of the trial both in the total material and in the patient group with proven acute myocardial infarction $(P<0.05)$. As expected there was a higher frequency of therapeutic failure during the first hour of the trial in both groups. Only the first 16 hours are represented in Fig. I, as the monitoring then was discontinued in some patients.

\section{Plasma levels}

The plasma concentrations (mean \pm SEM) in the

TABLE 3 Number of patients in each group with therapeutic failure per I-hour interval during first 6 hours after entry into trial

\begin{tabular}{|c|c|c|c|c|c|c|c|c|c|c|c|c|}
\hline \multirow{3}{*}{$\begin{array}{l}\text { Hours after } \\
\text { therapy start }\end{array}$} & \multicolumn{6}{|c|}{ Procainamide group } & \multicolumn{6}{|c|}{ Phenytoin group } \\
\hline & \multicolumn{2}{|c|}{ Proven $A M I^{\star}$} & \multicolumn{2}{|c|}{ Unproven $A M I^{\star}$} & \multicolumn{2}{|c|}{ All patients } & \multicolumn{2}{|c|}{ Proven $A M I^{\star}$} & \multicolumn{2}{|c|}{ Unproven $A M I^{\star}$} & \multicolumn{2}{|c|}{ All patients } \\
\hline & No. & Per cent & No. & Per cent & No. & Per cent & No. & Per cent & No. & Per cent & No. & Per cent \\
\hline I & $9 / 30$ & 30 & $I / 9$ & I I & $10 / 39$ & 26 & $14 / 28$ & 50 & $4 / 7$ & 57 & $18 / 35$ & $5 I$ \\
\hline 2 & $3 / 21$ & 14 & $0 / 8$ & 0 & $3 / 29$ & 29 & $4 / 14$ & 29 & $1 / 3$ & 33 & $5 / 17$ & 29 \\
\hline 3 & $2 / 18$ & I I & $0 / 8$ & 0 & $2 / 26$ & 8 & $2 / 10$ & 20 & $0 / 2$ & 0 & $2 / 12$ & 17 \\
\hline 4 & $1 / 16$ & 6 & $0 / 8$ & 0 & $I / 24$ & 4 & $0 / 8$ & 0 & $0 / 2$ & 0 & $0 / 10$ & 0 \\
\hline 5 & $2 / 15$ & 13 & $3 / 8$ & 38 & $5 / 23$ & 22 & $3 / 8$ & 38 & $0 / 2$ & 0 & $3 / 10$ & 30 \\
\hline 6 & $1 / 13$ & 8 & $0 / 5$ & 0 & $1 / 18$ & 6 & $1 / 5$ & 20 & $0 / 2$ & 0 & $\mathrm{I} / 7$ & 14 \\
\hline
\end{tabular}

Note: Seven patients, who developed suspected drug-induced side-effects immediately after the loading doses, are not included. $\star \mathrm{AMI}=$ acute myocardial infarction. 
TABLE 4 Type of ventricular arrhythmia at therapeutic failure

\begin{tabular}{llllll} 
Type of ventricular & arrhythmia \\
\hline Fre- & Multi- & Paired & $R / T$ & $V T$ & $V F$ \\
quent & focal & $V E B$ & $V E B$ & & \\
$V E B^{\star}$ & $V E B$ & & & &
\end{tabular}

\begin{tabular}{|c|c|c|c|c|c|c|}
\hline \\
\hline \multicolumn{7}{|c|}{$\begin{array}{l}\text { Procainamide group } \\
\text { Acute } \\
\text { myocardial } \\
\text { infarction }\end{array}$} \\
\hline \multicolumn{7}{|c|}{$\begin{array}{l}\text { Unproven } \\
\text { myocardial } \\
\text { infarction }\end{array}$} \\
\hline & & \\
\hline \multicolumn{7}{|l|}{ Phenytoin group } \\
\hline \multicolumn{7}{|l|}{$\begin{array}{l}\text { myocardial } \\
\text { infarction }\end{array}$} \\
\hline \multicolumn{7}{|l|}{$\begin{array}{l}\text { Unproven } \\
\text { myocardial } \\
\text { infarction }\end{array}$} \\
\hline $\begin{array}{l}(n=7) \\
\text { All patients }\end{array}$ & 3 & 3 & I & o & 0 & 0 \\
\hline$(n=35)$ & 8 & 12 & 12 & 2 & 2 & 0 \\
\hline
\end{tabular}

$\star$ VEB $=$ ventricular ectopic beat.

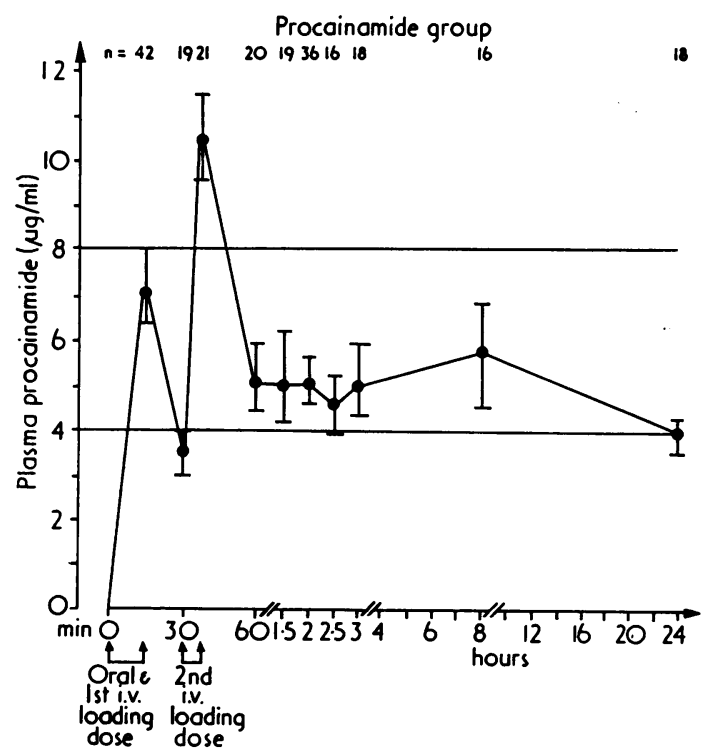

two treatment groups are given in Fig. 2. The apparent therapeutic range for both procainamide (Koch-Weser and Klein, 197I) and phenytoin (Bigger, Schmidt, and Kutt, 1968) are indicated. The mean plasma level of procainamide ranged from $17-29.7 \mu \mathrm{mol} / 1$ (4 to $7 \mu \mathrm{g} / \mathrm{ml})$ with the exception of the peak plasma concentration after the second intravenous loading dose, which reached 45.I $\mu \mathrm{mol} / \mathrm{l}(\mathrm{I} 0.6 \mu \mathrm{g} / \mathrm{ml})$. In the phenytoin group the fluctuation of the mean plasma level during the trial is smaller: during a period between about $I$ and 6 hours after the start of therapy the plasma level was fairly constantly around 36-40 $\mu \mathrm{mol} / \mathrm{l}$ (9 to ro $\mu \mathrm{g} / \mathrm{ml}$ ). Plasma levels (mean \pm SEM) during the first 2 hours of the trial in patients with and without demonstrated therapeutic failure are shown for the 2 groups in Fig. 3. The differences between patients with and without therapeutic failure reach statistical significance only for the phenytoin group and only at 2 hours after the start of therapy $(\mathrm{P}<0.0 \mathrm{I})$.

Table 5 gives the percentage of patients attaining each plasma level for both the procainamide and the phenytoin group at the time of therapeutic failure. The plasma concentrations are either the exact values or estimated from the known values immediately before and after the failure. Seventeen of 25 patients $(68 \%)$ in the phenytoin group against IO of 2I

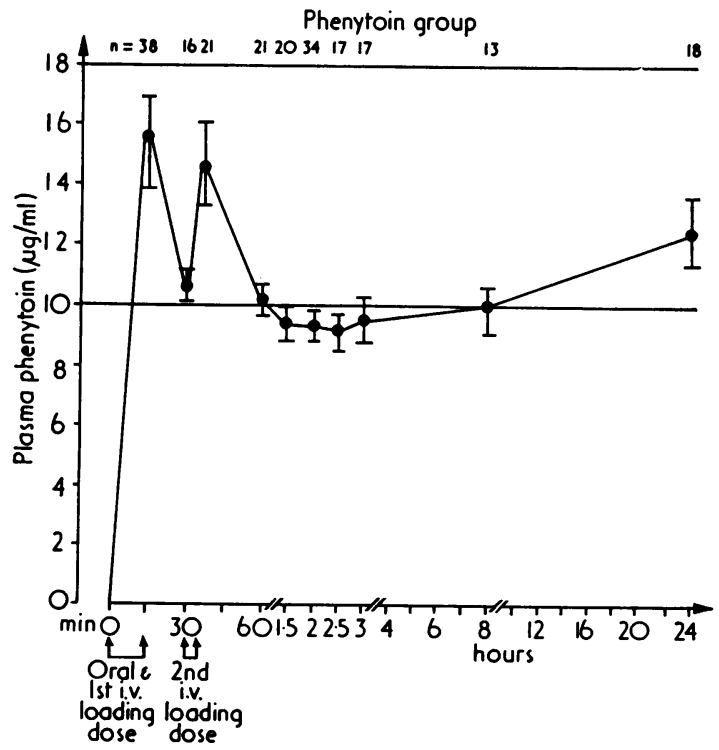

FIG. 2 Plasma concentrations of procainamide and phenytoin, in the two treatment groups (mean $\pm S E M)$. Apparent therapeutic ranges (see text) and number of patients at each sampling occasion are indicated. For conversion to SI units I $\mu \mathrm{g} / \mathrm{ml} \approx 4.25 \mu \mathrm{mol} / \mathrm{l}$; phenytoin $I \mu \mathrm{g} / \mathrm{ml} \approx 4$ $\mu \mathrm{mol} / \mathrm{l}$. 

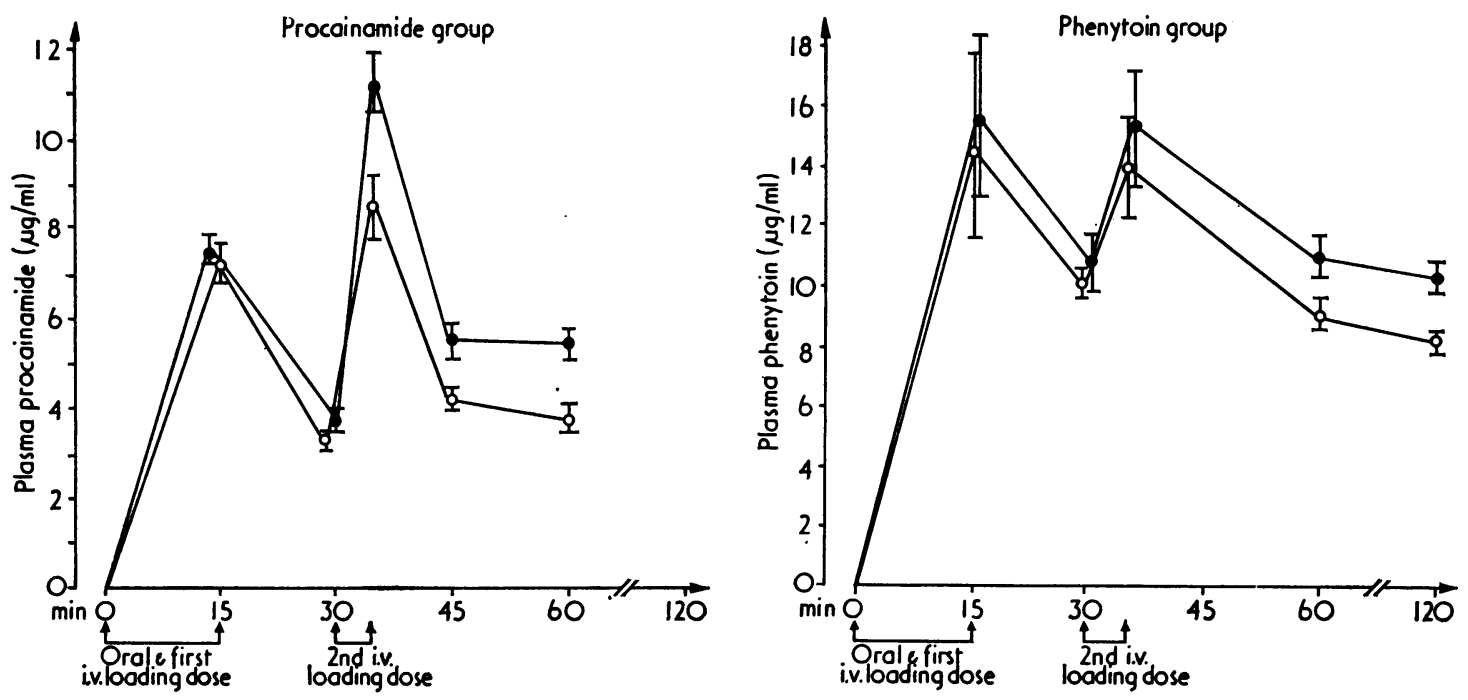

FIG. 3 Plasma concentrations of procainamide and phenytoin in batients with $(O)$ and without (O) therapeutic failure during the first 2 hours after therapy star Mean $\pm S E M$.) For conversion to SI units: procainamide I $\mu \mathrm{g} / \mathrm{ml} \approx 4.25 \mu \mathrm{mol} / \mathrm{l}$; phenytoin $I \mu \mathrm{g} / \mathrm{ml} \approx 4 \mu \mathrm{mol} / \mathrm{l}$.

TABLE 5 Number of patients at various plasma levels of drugs (observed or estimated when it was possible) at the moment of therapeutic failure

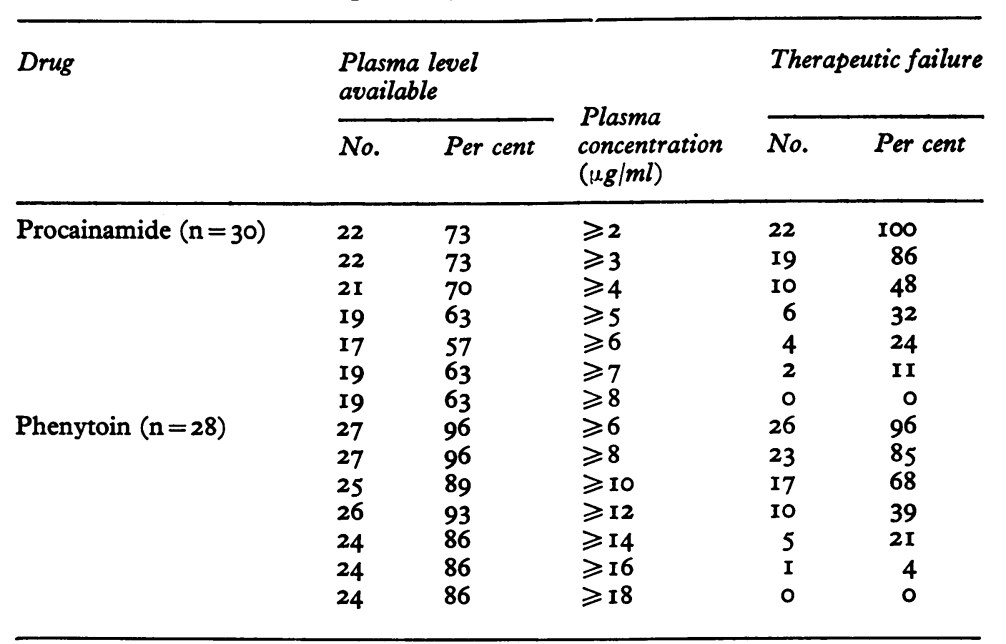

Conversion factors from SI Units to Traditional Units:

Procainamide: $\mathrm{I} \mu \mathrm{g} / \mathrm{ml} \approx 4.25 \mu \mathrm{mol} / 1$.

Phenytoin: $\mathrm{I} \mu \mathrm{g} / \mathrm{ml} \approx 4.0 \mu \mathrm{mol} / 1$.

patients $(48 \%)$ in the procainamide group had plasma concentrations higher than the minimum therapeutic level when therapeutic failure occurred.

\section{Side-effects}

Serious symptoms, possibly caused by the drug administered, occurred in 4 patients in each group and necessitated discontinuance of the therapy.

Procainamide group The first intravenous loading dose was interrupted because of vomiting, bradyarrhythmia, and hypotension in one case and 
because of the appearance of bundle-branch block in another. Maximum plasma concentrations were $18.7 \mu \mathrm{mol} / 1(4.4 \mu \mathrm{g} / \mathrm{ml})$ and $30.2 \mu \mathrm{mol}(7.1 \mu \mathrm{g} / \mathrm{ml})$, respectively. In the latter case, however, the bundlebranch block developed intermittently during the following 8 hours in connexion with pain and even at a plasma concentration of $3.4 \mu \mathrm{mol} / 1(0.8 \mu \mathrm{g} / \mathrm{ml})$. It, therefore, seems unlikely that the procainamide administration was the prime cause of the block. In one patient a fall in blood pressure from $160 / 100$ to $95 / 75 \mathrm{mmHg}$ (21.3/13.3 to $12.6 / 10.0 \mathrm{kPa})$ and a bradyarrhythmia occurred about to minutes after the second intravenous loading dose. The maximum plasma levels at the end of the two intravenous loading doses were $28.0 \mu \mathrm{mol} / 1(6.6 \mu \mathrm{g} / \mathrm{ml})$ and $22.1 \mu \mathrm{mol} / 1(5.2 \mu \mathrm{g} / \mathrm{ml})$ but were only $12.3 \mu \mathrm{mol} / 1$ $(2.9 \mu \mathrm{g} / \mathrm{ml})$ when the side-effects developed. Only intravenous and oral loading doses were given to one patient with heart failure and without confirmed acute myocardial infarction because of intermittently recorded junctional rhythm, which, however, also persisted during the following 16 hours and even on the next day during lignocaine infusion. The plasma level ranged between 27.2 and $34 \mu \mathrm{mol} / 1$ $(6.4$ and $8 \mu \mathrm{g} / \mathrm{ml})$.

Phenytoin group In 2 patients in this group the first intravenous loading dose was interrupted. In one case nausea, vertigo, a fall in blood pressure from $150 / 110 \mathrm{mmHg}(20.0 / 14.6 \mathrm{kPa})$ to $80 / 60$ $\mathrm{mmHg}$ (I0.6/8.0 kPa) and respiratory failure were the indications, while in the other they were nausea, vertigo, and junctional bradyarrhythmia. The maximum plasma levels were $41.6 \mu \mathrm{mol} / 1$ (10.4 $\mu \mathrm{g} / \mathrm{ml}$ ) and $84.4 \mu \mathrm{mol} / 1$ (2I.I $\mu \mathrm{g} / \mathrm{ml}$ ), respectively. In two other cases only the first intravenous loading dose was given because of nausea and vertigo in one case and bradyarrhythmia ( 35 beats/min) with increasing duration of the QRS complexes in the other. The maximum plasma levels were 51.2 $\mu \mathrm{mol} / 1(12.8 \mu \mathrm{g} / \mathrm{ml})$ and $79.2 \mu \mathrm{mol} / 1(19.8 \mu \mathrm{g} / \mathrm{ml})$ in these patients.

All the serious symptoms probably caused by the antiarrhythmic drugs developed in connexion with the intravenous loading dose. After discontinuance of the therapy all symptoms soon disappeared. None of these patients died while in hospital.

Eleven patients in the procainamide group and 6 patients in the phenytoin group developed hypotension within the first 3 hours of the trial. Hypotension was defined as a systolic blood pressure drop of $30 \mathrm{mmHg}(4.0 \mathrm{kPa})$ or more. In 3 of these patients in the procainamide group and in one patient in the phenytoin group there was a transient drop in systolic blood pressure to $<100 \mathrm{mmHg}$ $(<13.3 \mathrm{kPa})$ after the intravenous loading doses.
As a criterion of the existence or development of heart failure, the administration of diuretics and/or digitalis during the trial was used. In the procainamide group 6 patients received diuretic therapy compared to 20 patients in the phenytoin group. Three of these patients also received digitalis, one patient in the first group and two patients in the second.

Nausea and vomiting were observed in 5 patients in the procainamide group and in 6 patients in the phenytoin group. In the last group, pronounced vertigo (4 patients), junctional rhythm (2 patients), and bradyarrhythmias (2 patients) were also observed. Slight vertigo and local pain during the intravenous administration of phenytoin were very common. Junctional rhythm was also noticed in one patient in the procainamide group. No other adverse effects of importance were recorded.

\section{Mortality}

Five patients in the procainamide group died in hospital. One of the deaths occurred $I_{2} \frac{1}{2}$ hours after the start of the trial. The plasma level of procainamide was $14.9 \mu \mathrm{mol} / 1(3.5 \mu \mathrm{g} / \mathrm{ml})$. Necropsy showed cardiac rupture with pericardial tamponade. Two patients died during the first day in hospital. Both of them received lignocaine infusion because of the failure of procainamide therapy. In spite of the lignocaine therapy they developed ventricular tachycardia and ventricular fibrillation, respectively, and the circulation could not be re-established. One patient died on the 6th day (cardiac rupture) and one patient on the roth day (pulmonary embolism).

In the phenytoin group 4 patients died in the hospital. None of them died during the trial. Two patients with therapeutic failure, who were subsequently treated with lignocaine died of cardiogenic shock and cardiac rupture, respectively, on the first day. Another patient also died from cardiac rupture on the second day in hospital. One patient was found dead in bed 7 days after admission.

Thus, it is unlikely that any of these deaths were caused by toxic effects of the two trial drugs. Plasma levels of drugs have been determined in all of the patients who died during the first day in hospital and in all cases the levels were in the subtherapeutic range.

\section{Discussion}

Procainamide and phenytoin have many different properties both from an electrophysiological and a pharmacological point of view. When studied during similar circumstances in both digitalisintoxicated and normal dog heart, both atrioventricular and intraventricular conduction were depressed by procainamide while phenytoin had little 
or no effect on intraventricular conduction and even enhanced atrioventricular conduction (Helfant, Scherlag, and Damato, 1967a). These findings are in close agreement with those of other investigations (Kayden, Brodie, and Steele, 1957; Rosen et al., 1969; Damato et al., 1970; Josephson et al., 1974; Bissett et al., 1974; Scheinman et al., 1974).

The pharmacokinetic profiles of the two drugs differ considerably. Procainamide is absorbed more rapidly from the gastrointestinal tract than phenytoin (Svensmark, Schiller, and Buchthal, 1960; Arnold and Gerber, 1970; Koch-Weser and Klein, 1971). Phenytoin has a much higher affinity to plasma proteins (Lunde et al., 1970) and is almost completely metabolized in the liver (Svensmark et al., 1960; Glazko et al., 1969) while about 50 per cent of procainamide is excreted unchanged in the urine (Mark et al., 195I; Koch-Weser and Klein, 1971; Karlsson et al., 1974). The differences in protein binding and elimination explain the difference in plasma half-life, which is about 3 hours for procainamide (Koch-Weser and Klein, 197I) but as long as about $22 \pm 9$ hours for phenytoin (Arnold and Gerber, 1970). However, the need to administer procainamide every $3^{\text {rd }}$ or $4^{\text {th }}$ hour to keep plasma levels within the apparent therapeutic range has now been eliminated by development of sustained release preparations of the drug. The dosage interval can be doubled with this drug formulation (Fremstad et al., 1973; Karlsson, 1973; Arstila et al., 1974).

Experimentally, procainamide has been shown to effectively suppress ventricular arrhythmias (Mark et al., I95I; Gamble and Cohn, 1972). It was more effective than phenytoin when tested for ability to prevent ventricular fibrillation induced by coronary occlusion in dogs (Lown and Wolf, I971; Weisse et al., 1971). However, in other investigations, especially in the case of ventricular arrhythmias induced by digitalis, phenytoin has been very effective and has been proposed as the drug of choice on account of its electrophysiological properties (Helfant, Scherlag, and Damato, 1967b, 1968).

In some clinical trials the effectiveness in preventing ventricular arrhythmias has been demonstrated for both procainamide (Kayden et al., 1957; KochWeser et al., 1969; Schwartz et al., 1970; Giardina, Heissenbuttel, and Bigger, 1973) and phenytoin (Mercer and Osborne, 1967; Rosen, Lisak, and Rubin, 1967; Bigger et al., 1968; Helfant et al., 1969; Vajda et al., 1973). However, in one clinical study by Stone, Klein, and Lown (I97I), phenytoin had no protective effect at all when administered to Io patients with chronic ischaemic coronary disease with recurring life-threatening tachycardia. In that study phenytoin was given in large doses resulting in very high plasma levels and sometimes in central nervous side-effects.

Because of this great discrepancy in the published reports on the effectiveness of the two drugs, it was thought of value to perform a trial in the same patient material. In order to evaluate the drugs as adequately as possible, they were administered as soon as the arrhythmias appeared, in the first 8 hours of the patient's admission to the coronary care unit. The conventional lignocaine therapy was temporarily omitted during the study period. For practical and ethical reasons the study was not performed in a double-blind fashion. Continuous electrocardiograms during the trial were analysed, which enabled detection of rare but potentially dangerous arrhythmias, e.g. ventricular ectopic beats of $R$ on $T$ type. Though differentiation of arrhythmias in occurrence and type may often be difficult, the electrocardiographic material from this trial has been analysed only by the author, which should ensure a standardized interpretation.

Therapeutic failure, defined as the occurrence of the same kind of arrhythmias that were used to indicate initiation of treatment, was detected very frequently. In only 13 of the 81 patients ( $16 \%$ ) was no further ventricular arrhythmia calling for treatment detected during the trial period. Four of these patients belonged to the phenytoin group, and 9 to the procainamide group.

In the prophylactic trial by Koch-Weser et al. (1969) procainamide abolished about 30 per cent of ventricular arrhythmias compared to 21 per cent in this study. The continuous electrocardiographic recording in the present study provided a more sensitive method of detecting infrequent rhythm disturbances, which may account for the small difference in therapeutic effect. No corresponding trial for phenytoin has been found among the published reports.

During the first 2 hours after the initiation of therapy there was a significantly higher frequency of therapeutic failure in the phenytoin group. There was also a higher frequency of serious sideeffects, necessitating cessation of therapy in this group, despite the fact that procainamide loading doses mostly resulted in higher plasma levels. Thus, if both therapeutic efficiency and the incidence of side-effects are taken into consideration the advantages of procainamide are clear.

The mean plasma level of procainamide was possibly somewhat higher than that of phenytoin. However, the two drugs have quite different pharmacokinetic properties. Procainamide, even when given as a sustained release preparation, shows much greater fluctation in plasma levels during each dosage interval than phenytoin. This fact 
increases the risk both of adverse reactions at the time of peak plasma level and of therapeutic ineffectiveness at the time of minimum plasma concentration. Therefore, more important than the mean plasma levels of the drugs is the plasma concentration of each trial drug at the moment of the therapeutic failure in each case. There were about 20 per cent more patients in the phenytoin than in the procainamide group who showed a plasma concentration higher than the suggested lower limit of therapeutic range. Thus, the observed greater effectiveness of procainamide cannot be explained by disparity in plasma levels of the two trial drugs. The frequency both of minor and more serious adverse effects was at least equal if not more frequent in the phenytoin group. One reason for the low frequency of sideeffects during procainamide therapy may be that the drug was administered as a sustained release preparation.

Though no significant differences occurred, there seems to be a tendency to a higher frequency of hypotension in the procainamide group and of heart failure in the phenytoin group. Both hypotension and heart failure frequently occur after an acute myocardial infarction, but the difference between the two groups cannot be explained in this way. However, the observed differences are in good agreement with preliminary results from a comparative haemodynamic investigation in patients with congenital heart lesions (E. Karlsson, unpublished observations). This study suggested that procainamide had a more pronounced peripheral vasodilating effect while phenytoin had a greater negative inotropic effect.

The overall results of this investigation, from the point of view of both anti-arrhythmic efficacy and side-effects during short-term therapy, clearly demonstrate the advantage of procainamide therapy. However, even in the group treated with this drug there was an unexpectedly high frequency of therapeutic failure often associated with supposedly therapeutic plasma concentrations. Thus, in many patients the optimum plasma level must be individually tailored and may depend on the type of arrhythmia and the disease state. A good service for monitoring the plasma levels may be very helpful in this respect.

This study was supported by grants from the Swedish National Association against Heart and Chest Diseases. The sustained-release preparation of procainamide was supplied by AB Hässle, Sweden.

\section{References}

Arnold, K., and Gerber, N. (1970). The rate of decline of diphenylhydantoin in human plasma. Clinical Pharmacology and Therapeutics, 11, I21.
Arstila, M., Katila, M., Sundquist, H., Anttila, M., Pere, E., and Tikkanen, R. (1974). Dosage, plasma concentration and antiarrhythmic effect of procainamide in sustainedrelease tablets. Acta Medica Scandinavica, 195, 217.

Bennet, M. A., and Pentecost, B. L. (1972). Warning of cardiac arrest due to ventricular fibrillation and tachycardia. Lancet, I, I35I.

Berlin, A., Agurell, S., Borgå, O., Lund, L., and Sjöqvist, F. (1972). Micromethod for the determination of diphenylhydantoin in plasma and cerebrospinal fluid - a comparison between a gas chromatographic and a spectrophotometric method. Scandinavian fournal of Clinical and Laboratory Investigation, 29, 281.

Bigger, J. T., Jr., Schmidt, D. H., and Kutt, H. (1968). Relationship between the plasma level of diphenylhydantoin sodium and its cardiac antiarrhythmic effects. Circulation, 38, 363 .

Bissett, J. K., de Soyza, N. D. B., Kane, J. J., and Murphy, M. L. (1974). Improved intraventricular conduction of premature beats after diphenylhydantoin. American fournal of Cardiology, 33, 493.

Bleifeld, W., and Merx, W. (1970). Primäre und sekundäre Arrhythmien beim Herzinfarkt. Verhandlungen der Deutschen Gesellschaft für innere Medizin, 76, 611 .

Damato, A. N., Berkowitz, W. D., Patton, R. D., and Lau, S. H. (1970). The effect of diphenylhydantoin on atrioventricular and intraventricular conduction in man. American Heart fournal, 79, 5 I.

Dhurandhar, R. W., MacMillan, R. L., and Brown, K. W. G. (I97I). Primary ventricular fibrillation complicating acute myocardial infarction. American fournal of Cardiology, 27, 347.

Fremstad, D., Dahl, S., Jacobsen, S., Lunde, P. K. M., Nådland, K. J., Marthinsen, A. A., Waaler, T., and Landmark, K. H. (1973). A new sustained-release tablet formulation of procainamide. European fournal of Clinical Pharmacology, 6, $25 \mathrm{I}$.

Gamble, O. W., and Cohn, K. (1972). Effect of propranolol, procainamide, and lidocaine on ventricular automaticity and reentry in experimental myocardial infarction. Circulation, 46, 498.

Giardina, E.-G. V., Heissenbuttel, R. H., and Bigger, J. T., Jr. (1973). Intermittent intravenous procaine amide to treat ventricular arrhythmias. Correlation of plasma concentration with effect on arrhythmia, electrocardiogram, and blood pressure. Annals of Internal Medicine, 78, 183.

Glazko, A. J., Chang, T., Baukema, J., Dill, W. A., Goulet, J. R., and Buchanan, R. A. (1969). Metabolic disposition of diphenylhydantoin in normal human subjects following intravenous administration. Clinical Pharmacology and Therapeutics, 10, 498.

Helfant, R. H., Scherlag, B. J., and Damato, A. N. (I967a). The electrophysiological properties of diphenylhydantoin sodium as compared to procaine amide in the normal and digitalis-intoxicated heart. Circulation, 36, 108.

Helfant, R. H., Scherlag, B. J., and Damato, A. N. (1967b). Protection from digitalis toxicity with the prophylactic use of diphenylhydantoin sodium. Circulation, 36, I 19.

Helfant, R. H., Scherlag, B. J., and Damato, A. N. (I968). Diphenylhydantoin prevention of arrhythmias in the digitalis-sensitized dog after direct-current cardioversion. Circulation, 37, 424.

Helfant, R. H., Seuffert, G. W., Patton, R. D., Stein, E., and Damato, A. N. (1969). The clinical use of diphenylhydantoin (Dilantin) in the treatment and prevention of cardiac arrhythmias. American Heart fournal, 77, 315.

Josephson, M. E., Caracta, A. R., Ricciutti, M. A., Lau, S. H., and Damato, A. N. (I974). Electrophysiologic properties of procainamide in man. American fournal of Cardiology, 33, 596 . 
Julian, D. G., Valentine, P. A., and Miller, G. G. (1964). Disturbances of rate, rhythm and conduction in acute myocardial infarction. American fournal of Medicine, 37, 915.

Karlsson, E. (1973). Plasma levels of procaine amide after administration of conventional and sustained-release tablets. European fournal of Clinical Pharmacology, 6, 245.

Karlsson, E., Molin, L., Norlander, B., and Sjöqvist, F. (1974). Acetylation of procaine amide in man studied with a new gas chromatographic method. British fournal of Clinical Pharmacology, $1,467$.

Kayden, H. J., Brodie, B. B., and Steele, J. M. (1957). Procaine amide. A review. Circulation, 15, 118.

Koch-Weser, J., and Klein, S. W. (1971). Procain amide dosage schedules, plasma concentrations, and clinical effects. Fournal of the American Medical Association, 215, I454.

Koch-Weser, J., Klein, S. W., Foo-Canto, L. L., Kastor, J. A., and DeSanctis, R. W. (1969). Antiarrhythmic prophylaxis with procainamide in acute myocardial infarction. New England fournal of Medicine, 281, 1253.

Lown, B., Fakhro, A. M., Hood, W. B., and Thorn, G. W. (1967). The coronary care unit: new perspectives and directions. Fournal of the American Medical Association, 199, 188.

Lown, B., and Wolf, M. (1971). Approaches to sudden death from coronary heart disease. Circulation, 44, 130.

Lunde, P. K. M., Rane, A., Yaffe, S. J., Lund, L., and Sjöqvist, F. (1970). Plasma protein binding of diphenylhydantoin in man. Clinical Pharmacology and Therapeutics, II, 846.

Mark, L. C., Kayden, H. J., Steele, J. M., Cooper, J. R., Berlin, I., Rovenstine, E. A., and Brodie, B. B. (I95I). The physiological disposition and cardiac effects of procainamide. fournal of Pharmacology and Experimental Therapeutics, 102, 5 .

Mercer, E. N., and Osborne, J. A. (1967). The current status of diphenylhydantoin in heart disease. Annals of Internal Medicine, 67, 1084 .

Merx, W., Effert, S., Bleifeld, W., and Vlachakis, N. (197I). Vorzeitigheitsindex beim Herzinfarkt. Deutsche medizinische Wochenschrift, 96, I903.
Mogensen, L., (1970). Ventricular tachyarrhythmias and lignocaine prophylaxis in acute myocardial infarction. Acta Medica Scandinavica, 188, Suppl. 513.

Rosen, M., Lisak, R., and Rubin, I. L. (1967). Diphenylhydantoin in cardiac arrhythmias. American fournal of Cardiology, 20, 674.

Rosen, K. M., Lisi, K. R., Berkowitz, W. D., Lau, S. H., and Damato, A. N. (1969). The effects of procaine amide on atrioventricular and intraventricular conduction in man (abstract). Circulation, 39 and 40, Suppl. III, 173.

Scheinman, M. M., Weiss, A. N., Shafton, E., Benowitz, N., and Rowland, M. (1974). Electrophysiologic effects of procaine amide in patients with interventricular conduction delay. Circulation, 49, 522.

Schwartz, M. L., Webb, N. C., Covino, B. G., Finck, E. M., and Haider, B. (1970). Comparative antiarrhythmic effects of intravenously administered lidocaine and procainamide and orally administered quinidine. American fournal of Cardiology, 26, 520.

Stone, N., Klein, M. D., and Lown, B. (1971). Diphenylhydantoin in the prevention of recurring ventricular tachycardia. Circulation, 43, 420.

Svensmark, O., Schiller, P. J., and Buchthal, F. (1960). 5.5-diphenylhydantoin (Dilantin) blood levels after oral or intravenous dosage in man. Acta Pharmacologica et Toxicologica, 16, 331.

Vajda, F. J. E., Prineas, R. J., Lovell, R. R. H., and Sloman, J. G. (I973). The possible effect of long-term high plasma levels of phenytoin on mortality after acute myocardial infarction. European fournal of Clinical Pharmacology, 5, 138.

Weisse, A. B., Moschos, C. B., Passannante, A. J., Kahn, M. I., and Regan, T. J. (197I). Relative effectiveness of three antiarrhythmic agents in the treatment of ventricular arrhythmias in experimental acute myocardial ischemia. American Heart fournal, 81, 503.

Requests for reprints to Dr. Erling Karlsson, Division of Cardiology, Department of Internal Medicine, Medical School, Linköping University, S-581 85 Linköping, Sweden. 